\title{
SPECTROSCOPIC EXPLORATION OF 2\% COPPER OXIDE DOPED BINARY ALKALI BOROSILICATE GLASS
}

\author{
Nagamani $^{1,2,} \bowtie$ and C. Srinivasu ${ }^{1,3}$ \\ ${ }^{1}$ Department of Physics, Krishna University, Machili patnam-521 001,(Andhra Pradesh) India. \\ ${ }^{2}$ Department of Physics,Dr.LHR Government Degree College, Mylavaram-521231, \\ (Andhra Pradesh) India. \\ ${ }^{3}$ Department of Physics, Andhra Loyola College, Vijayawada - 520 004, (Andhra Pradesh) India. \\ ${ }^{\square}$ Corresponding Author: nagamani1411@gmail.com
}

\begin{abstract}
Glasses are prepared with the oldest accepted technique of melting the silica, boron oxide and alkali oxides with $2 \%$ copper oxide and quenching in air. XRD, SEM with EDX, optical methods are employed to study the microstructure of the material. The ductile nature of glass is observed from DTA studies. Glass formation is confirmed by X-ray diffraction spectra. The measured band gaps from both reflectance spectra and absorption spectra are compared and show they are in good agreement. To know the degree of the covalency of bonds, bonding parameters are calculated from EPR data. The Covalency of bonds in host glasses influences the Luminescence emission of $\mathrm{Cu}^{2+}$ ions in the visible region. The molecular structure of glasses is studied using FTIR.The covalent nature of molecular orbitals and molecular structure in the prepared samples is analysed systematically. Also, the various physical properties evaluated concerning the concentration of Alkali ions are reported. The covalent nature of glasses is observed from metallisation criterion.
\end{abstract}

Keywords: Borosilicate Glass, Melt-Quench Method, Spectroscopic Techniques, Covalent Nature, Electron Paramagnetic Resonance.

RASĀYANJ. Chem., Vol. 14, No.3, 2021

\section{INTRODUCTION}

Borosilicate glasses are well thought of materials for their huge melting points, non-corrosiveness and bioactive nature. ${ }^{1-3}$ The properties of any material depending on its composition, chemical bond and molecular structure. In the present paper authors prepared borate glasses with alkali mixed of composition $38 \mathrm{SiO}_{2}-30 \mathrm{~B}_{2} \mathrm{O}_{3}-\mathrm{xNa}_{2} \mathrm{O}-(30-\mathrm{x}) \mathrm{K}_{2} \mathrm{O}-2 \mathrm{CuO}$ (where mol\% $\mathrm{x}=5$ to 25 , of five samples). On these glasses, the structural, spectroscopic studies are carried out systematically with a special focus on the environmental chemical bonds formed in the composition. For a better understanding of the structure of the glasses, XRD, SEM, EDX, DTA, Optical absorption technique, Photo Luminescence, EPR, FTIR techniques are employed. Many researchers reported Calibration techniques like Kubelka-Munk function makes quantitative Diffuse Reflectance Spectroscopy (DRS) technique is competitive with absorption spectroscopy in some cases. ${ }^{4}$ Literature reveals the energy gap magnitudes are extracted from reflectance spectra similar as in absorption spectra with Tauc plots. ${ }^{5,6}$

Further, it is known that Copper has multi oxidation states $+1,+2,+3$ like other transition metals. Out of which +2 oxidation states are most stable and have paramagnetic nature. $\mathrm{Cu}^{2+}$ ion electronic configuration is $3 \mathrm{~d}^{9}$. The surrounding ligand structure of $\mathrm{Cu}^{2+}$ ions can be studied with EPR. Spectroscopic properties of transition metals are affected largely by their local environment. In another word, one can say the transition metal copper helps explore the structure of the glass.

In the present work, the authors attempted to measure bandgaps from both reflectance spectra and absorption spectra are compared. The degree of the covalency of bonds and bonding parameters are evaluated from EPR data. The Covalency of bonds in host glasses also influences the Luminescence emission of $\mathrm{Cu}^{2+}$ ions in the visible region. ${ }^{7}$ The various bonds that are present in the structure of the studied glasses are reported using FTIR. 
RASĀYAN J. Chem.

Vol. 14 | No. 3 |2136-2146| July - September | 2021

\section{EXPERIMENTAL}

The various constituents and assigned codes involved in the preparation of glass are specified in Table1.The studied glasses are prepared by melt- quenching method. Analytical-grade reagents of $\mathrm{SiO}_{2}, \mathrm{~B}_{2} \mathrm{O}_{3}$ (99.5 - Loba) and $\mathrm{Na}_{2} \mathrm{O}, \mathrm{K}_{2} \mathrm{O}$ anhydrous carbonates, $2 \mathrm{~mol} \% \mathrm{CuO}$ are weighed commensurable to their mol\% as shown in Table - 1 for each glass. The powdered batch chemicals of glass are melted at $1100^{\circ} \mathrm{C}$ for a one-hour duration of time in a vertical furnace. The molten form of the material is quickly cooled in air pouring on a brass plate. To eliminate internal stress the obtained glasses are annealed in an oven at $350^{\circ} \mathrm{C}$ for 3 hours.

The non-periodic arrangement of atoms in glasses is examined by XRD obtained from an X-ray diffractometer. Exterior surface smoothness and structural inhomogeneities are observed using Field emission SEM and X-ray energy dispersive analysis. The glass density is measured by density meter. To find out the electron transitions of energies nearer to bandgap are obtained using Perkin Elmer lambda 950 UV-VIS-NIR spectrophotometer. Magnetic resonance is measured and noted using EPR spectrometer. JY Fluorolog-3-11 fluorimeter is used to record photoluminescence spectra of glasses.

Table -1: Details of Chemical Composition of $38 \mathrm{SiO}_{2}-30 \mathrm{~B}_{2} \mathrm{O}_{3}-\mathrm{xNa} \mathrm{Na}_{2} \mathrm{O}-(30-\mathrm{x}) \mathrm{K}_{2} \mathrm{O}-2 \mathrm{CuO}(\mathrm{x}=5,10,15,20,25)$

\begin{tabular}{c|c}
\hline Glass Code & Constituents of Glass (All in mol\%) \\
\hline $\mathrm{Cu}_{5}$ & $38 \mathrm{SiO}_{2}-30 \mathrm{~B}_{2} \mathrm{O}_{3}-5 \mathrm{Na}_{2} \mathrm{O}-25 \mathrm{~K}_{2} \mathrm{O}-2 \mathrm{CuO}$ \\
\hline $\mathrm{Cu}_{10}$ & $38 \mathrm{SiO}_{2}-30 \mathrm{~B}_{2} \mathrm{O}_{3}-10 \mathrm{Na}_{2} \mathrm{O}-20 \mathrm{~K}_{2} \mathrm{O}-2 \mathrm{CuO}$ \\
\hline $\mathrm{Cu}_{15}$ & $38 \mathrm{SiO}_{2}-30 \mathrm{~B}_{2} \mathrm{O}_{3}-15 \mathrm{Na}_{2} \mathrm{O}-15 \mathrm{~K}_{2} \mathrm{O}-2 \mathrm{CuO}$ \\
\hline $\mathrm{Cu}_{20}$ & $38 \mathrm{SiO}_{2}-30 \mathrm{~B}_{2} \mathrm{O}_{3}-20 \mathrm{Na}_{2} \mathrm{O}-10 \mathrm{~K}_{2} \mathrm{O}-2 \mathrm{CuO}$ \\
\hline $\mathrm{Cu}_{25}$ & $38 \mathrm{SiO}_{2}-30 \mathrm{~B}_{2} \mathrm{O}_{3}-25 \mathrm{Na}_{2} \mathrm{O}-5 \mathrm{~K}_{2} \mathrm{O}-2 \mathrm{CuO}$ \\
\hline
\end{tabular}

\section{Physical Parameters}

Prepared glasses Physical properties are assessed utilizing density, molecular weights (M) of glass by traditional formulae ${ }^{8}$, which are specified in Table-2. From glass samples $\mathrm{Cu}_{5}$ to $\mathrm{Cu}_{25}$, the mol\% of potassium $\left(\mathrm{K}^{+}\right)$ions decrease by $5 \%$ and monovalent sodium ions replace potassium ions. Molar volume decreases due to the more electropositive potential of monovalent potassium ions compared with sodium ions. With this effect ionic concentration, the intensity of ionic Field increases and separation between ions and polaron radius decreases. The evaluated values of physical parameters are presented in Table- 2 . Making use of indirect band energies from Table-3, refractive index and Molar Polarizability and Metallization Criterion are also evaluated. ${ }^{9} \frac{\mathrm{Rm}}{\mathrm{Vm}}<1$ for all studied glasses indicates their nonmetallic nature. Metallization criterion $\mathrm{M}$ value is proportional to the material bandgap. $\mathrm{Cu}_{10}$ shows more ionic nature among the other studied glasses from $\frac{R m}{V m}$ values.

Table-2: Physical Parameters of $38 \mathrm{SiO}_{2}-30 \mathrm{~B}_{2} \mathrm{O}_{3}-\mathrm{xNa} 2 \mathrm{O}-(30-\mathrm{x}) \mathrm{K}_{2} \mathrm{O}-2 \mathrm{CuO}$ Glasses

\begin{tabular}{|c|c|c|c|c|c|}
\hline \multirow{2}{*}{ Physical Parameter(units) } & \multicolumn{5}{|c|}{ Glasscode } \\
\hline & $\mathrm{Cu}_{5}$ & $\mathrm{Cu}_{10}$ & $\mathrm{Cu}_{15}$ & $\mathrm{Cu}_{20}$ & $\mathrm{Cu}_{25}$ \\
\hline Average molecular weight $(\mathrm{g} / \mathrm{mol})$ & 71.95 & 70.34 & 68.73 & 67.12 & 65.51 \\
\hline Density $\rho\left(\mathrm{g} / \mathrm{cm}^{3}\right)$ & 2.601 & 2.595 & 2.591 & 2.587 & 2.586 \\
\hline molar volume $\left(\mathrm{cm}^{3}\right)$ & 27.9 & 27.1 & 26.5 & 25.9 & 25.3 \\
\hline Transition metal ion concentration & 7.91 & 8.08 & 8.26 & 8.44 & 8.64 \\
\hline Inter ionic distance $r_{i}\left(A^{o}\right)$ & 2.33 & 2.31 & 2.30 & 2.28 & 2.26 \\
\hline Polaron radius $r_{p}\left(A^{o}\right)$ & 0.94 & 0.93 & 0.92 & 0.92 & 0.91 \\
\hline Field strength $\mathrm{F}\left(10^{15} \mathrm{~cm}^{2}\right)$ & 2.27 & 2.30 & 2.33 & 2.37 & 2.41 \\
\hline Refractive index (at band edge) & 1.75 & 1.78 & 1.75 & 1.76 & 1.75 \\
\hline Molar Refraction (Rm) & 16.7 & 17.4 & 15.9 & 15.6 & 15.2 \\
\hline Molar Polarizability & 6.60 & 6.91 & 6.32 & 6.21 & 6.04 \\
\hline$\frac{R m}{V m}$ & 0.601 & 0.643 & 0.601 & 0.603 & 0.601 \\
\hline Metallization Criterion (M) & 0.397 & 0.357 & 0.399 & 0.397 & 0.399 \\
\hline
\end{tabular}




\section{Micro Structure Analysis Techniques}

The XRD spectrumFig.-1ofcupric ions doped glass $\mathrm{Cu}_{15}$ shows clearly it consists of the broad scattered band and no characteristic peaks. This ensures the non- crystallinity of the materials.

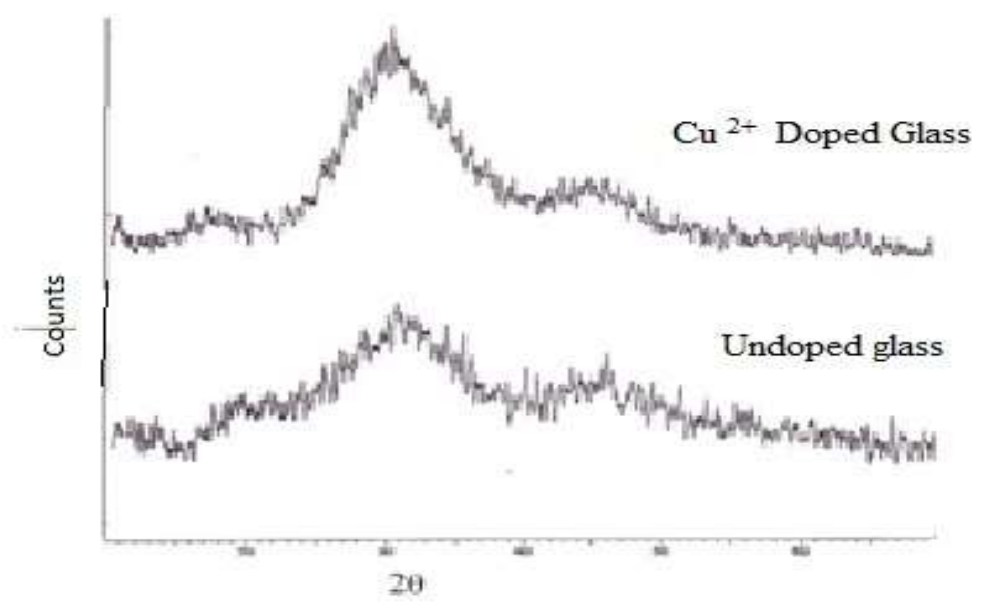

Fig.-1: XRD Spectra of Undoped $40 \mathrm{SiO}_{2}-30 \mathrm{~B}_{2} \mathrm{O}_{3}-15 \mathrm{Na}_{2} \mathrm{O}-15 \mathrm{~K}_{2} \mathrm{O}$ Glass and $\mathrm{CuO}$ Doped Glass

In a comparison of SEM pictures( two sets of magnifications) in Fig.-2, the surface structure of undoped glass and $\mathrm{Cu}_{15}$ glass, It is noticed that the glass texture becomes rough by embedding $\mathrm{CuO}$. This informs structural changes that may occur in the doped glass.
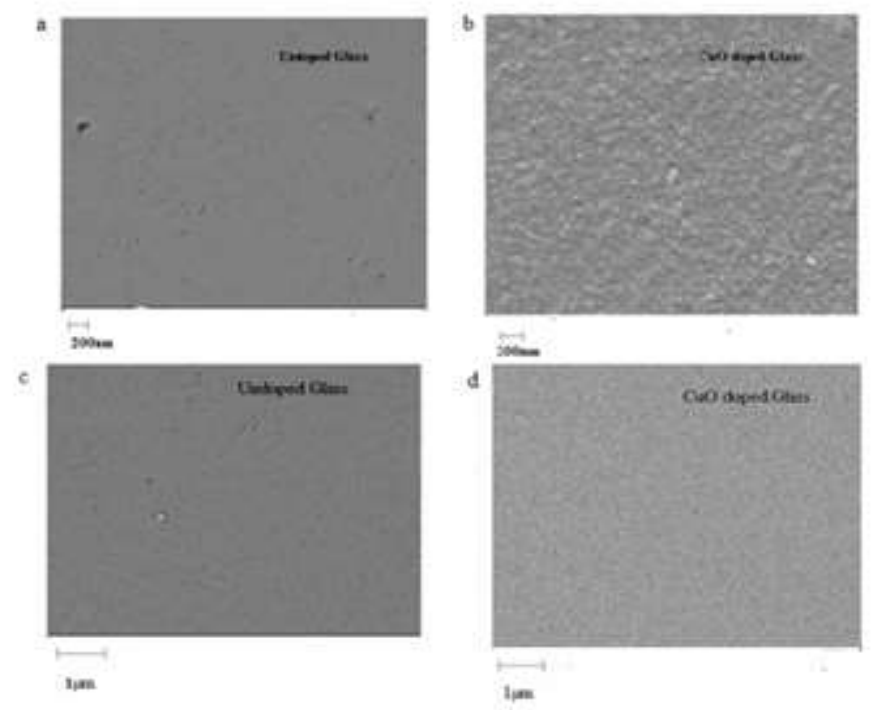

Fig.-2: (a), (b) $25 \mathrm{~K}$ times magnified SEM pictures of $40 \mathrm{SiO}_{2}-30 \mathrm{~B}_{2} \mathrm{O}_{3}-15 \mathrm{Na}_{2} \mathrm{O}-15 \mathrm{~K}_{2} \mathrm{O}$ undoped and Cupric oxide doped glass (c),(d) 10,000 times enlarged SEM pictures of without cupric oxide and with cupric oxide glass.

EDX spectra (Energy Dispersive X-Ray spectroscopy) for $\mathrm{Cu}_{15}$ glass is shown in Fig.-3 all the elements present in glass and the elements weight $\%$ and atomic $\%$ are almost the same as the true composition and details are shown in Fig.-3.

\section{Optical Bandgap Measurement}

Both Optical Absorption and DRS (Diffuse Reflectance Spectroscopy) techniques are utilized to study the energy gaps that occur in the present glass samples.

\section{Optical Absorption Technique}

The Optical absorption spectra of $\mathrm{Cu}^{2+}$ ions in present glasses in the wavelength region $200 \mathrm{~nm}-1300 \mathrm{~nm}$ are recorded in Fig.-4a. This spectrum reveals a lone intense wide-ranging band expected of ${ }^{2} \mathrm{~B}_{1 \mathrm{~g}} \rightarrow{ }^{2} \mathrm{~B}_{2 \mathrm{~g}}$ 
transition in all glasses. ${ }^{10,11}$ This wide and asymmetric absorption band from 450nm - 900nm partially covers the other absorption bands. A slight nonlinear change in the peak position of the band is observed from Fig.-4a). This is due to the ligand field effect on central metal cation $\mathrm{Cu}^{2+}$ with a change in $\mathrm{Na} / \mathrm{K}$ alkali ratio.

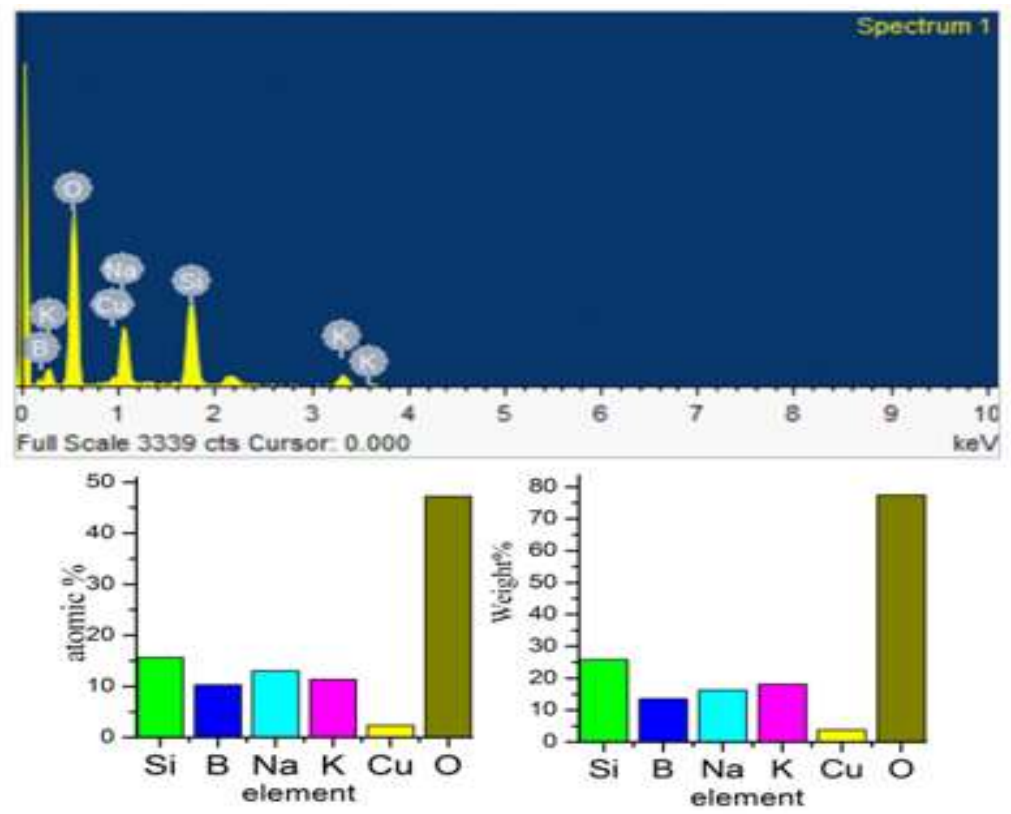

Fig.-3: EDX Spectrum of $38 \mathrm{SiO}_{2}-30 \mathrm{~B}_{2} \mathrm{O}_{3}-15 \mathrm{Na}_{2} \mathrm{O}-15 \mathrm{~K}_{2} \mathrm{O}-2 \mathrm{CuO}$ Glass

Applying, Tauc Optical absorption technique ${ }^{12,13}$ of noncrystalline materials, Tauc plots of absorption are drawn. The related Tauc plots of absorption data are depicted in Fig.-4b, 4c and 4d. In these plots, optical absorption coefficient $\alpha(v)$, optical band energies (for both direct, indirect transitions) are estimated with standard expressions which involve the glass thickness and absorbed photon intensity. $\mathrm{E}_{\text {direct }} \mathrm{E}_{\text {indirect }}$ implies that the phonon-assisted oblique transitions need less energy compared with the vertical allowed photon transitions. Along with these energies, Urbach energy, the mean energy of defected states is also reported.

Cupric ion has $3 \mathrm{~d}^{9}$ configuration. $\mathrm{Cu}^{2+}$ ion is 6 -coordinated octahedral complex. The trans ligands on $\mathrm{z}-$ axis experience less force by nuclear charge and the ligands in $x-y$ plane more. These two long bonds produce tetragonal elongation to $\mathrm{Cu}^{2+}$ ion octahedron structure. The Energy level picture of $3 \mathrm{~d}^{9}$ electron is illustrated in Fig. -5 with the recorded transition in reported glasses.

\section{DRS Technique}

The Tauc plots of reflectance spectra are studied Using Kubelka - Munk function relations with scattering coefficient $S$ and absorption spectroscopy band gap $\mathrm{E}_{\mathrm{opt}}$. The corresponding plots are shown in Fig.-6a, $6 \mathrm{~b}, 6 \mathrm{c}, 6 \mathrm{~d}$. The band gaps deduced corresponding to both Reflectance and absorption spectra plots are found to be nearly equal. These values are tabulated in Table -3 .

Table-3: Comparison of Optical Bandgaps from Absorbance and Reflectance Data

\begin{tabular}{c|c|c|c|c|c|c|c|c}
\hline \multirow{2}{*}{$\begin{array}{c}\text { Glass } \\
\text { Code }\end{array}$} & $\begin{array}{c}\text { Band } \\
\text { Position } \\
(\mathrm{nm})\end{array}$ & $\begin{array}{c}\text { Cut-off } \\
\text { Wave } \\
\text { Length } \\
\text { (nanometer) }\end{array}$ & $\begin{array}{c}\text { Absorbance Plots } \\
\text { Direct Energy } \\
\text { (electron volt) }\end{array}$ & $\begin{array}{c}\text { Indirect } \\
\text { Energy } \\
\text { Gap (eV) }\end{array}$ & $\begin{array}{c}\text { Urbach } \\
\text { Energy } \\
(\mathrm{eV})\end{array}$ & $\begin{array}{c}\text { Direct } \\
\text { Band Gap } \\
(\mathrm{eV})\end{array}$ & $\begin{array}{c}\text { Indirect } \\
\text { Energy } \\
(\mathrm{eV})\end{array}$ & $\begin{array}{c}\text { Urbach } \\
\text { Energy } \\
(\mathrm{elctronVo} \\
\mathrm{tt})\end{array}$ \\
\hline $\mathrm{Cu}_{5}$ & 816 & 416 & 3.34 & 3.15 & 0.28 & 3.4 & 3.01 & 0.33 \\
\hline $\mathrm{Cu}_{10}$ & 826 & 470 & 2.87 & 2.55 & 0.42 & 3.05 & 2.45 & 0.43 \\
\hline $\mathrm{Cu}_{15}$ & 796 & 390 & 3.44 & 3.19 & 0.29 & 3.5 & 3.20 & 0.34 \\
\hline $\mathrm{Cu}_{20}$ & 816 & 440 & 3.37 & 3.15 & 0.35 & 3.3 & 2.93 & 0.32 \\
\hline $\mathrm{Cu}_{25}$ & 814 & 393 & 3.43 & 3.18 & 0.31 & 3.5 & 3.27 & 0.32 \\
\hline
\end{tabular}


RASĀYAN J. Chem.

Vol. 14 | No. 3 |2136-2146| July - September | 2021
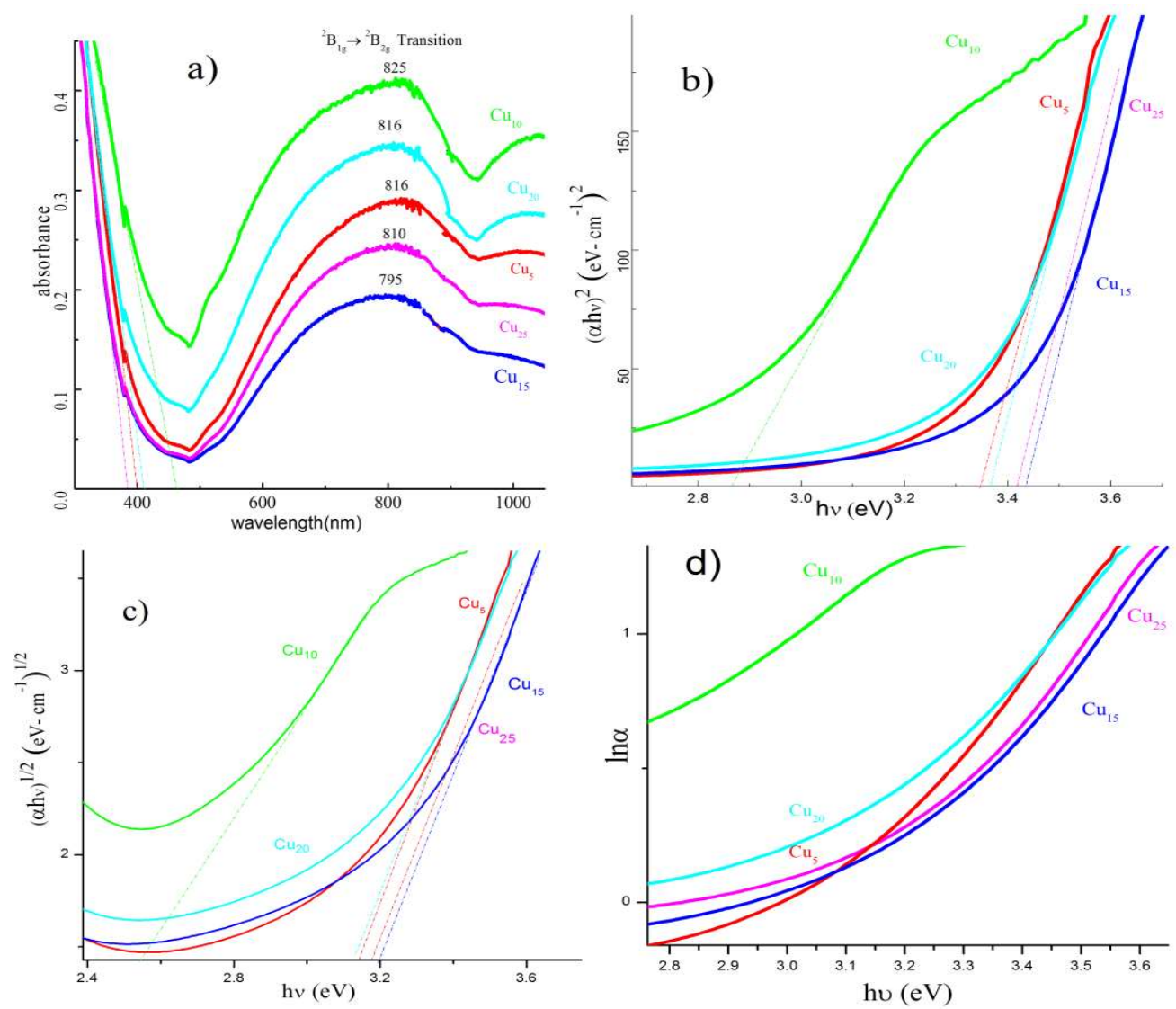

Fig.-4: (a) Absorption spectra of $38 \mathrm{SiO}_{2}-30 \mathrm{~B}_{2} \mathrm{O}_{3}-\mathrm{xNa}_{2} \mathrm{O}-(30-\mathrm{x}) \mathrm{K}_{2} \mathrm{O}-2 \mathrm{CuO}$ glasses;

Tauc absorption graphs to evaluate (b) direct energy gaps; (c) indirect energy gaps ; (d) Urbach energy of $38 \mathrm{SiO}_{2}-$ $30 \mathrm{~B}_{2} \mathrm{O}_{3}-\mathrm{xNa}_{2} \mathrm{O}-(30-\mathrm{x}) \mathrm{K}_{2} \mathrm{O}-2 \mathrm{CuO}$ reported glasses

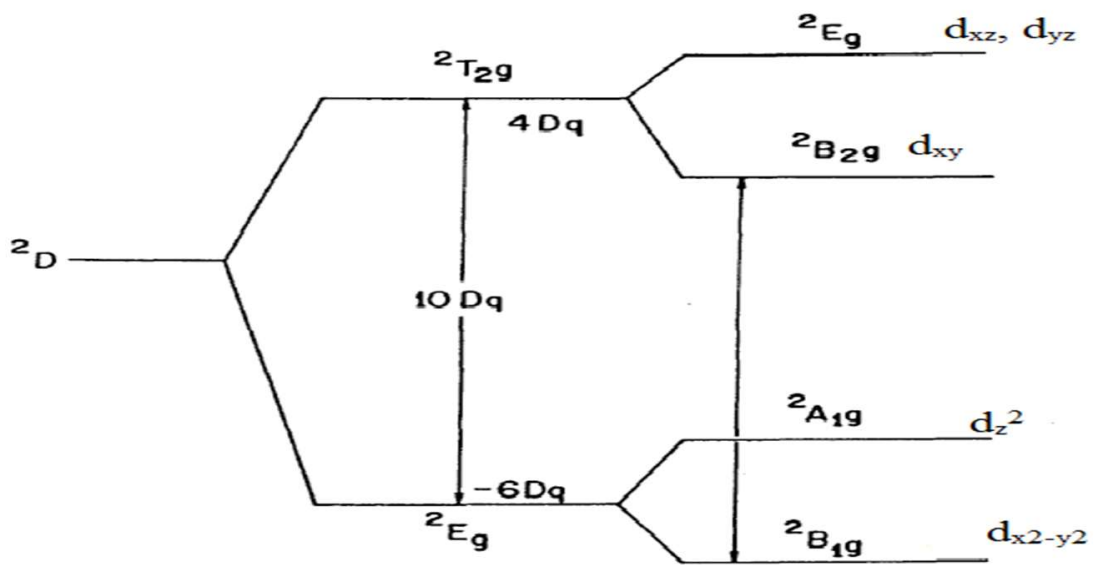

Fig.-5: Energy Level picture of $3 \mathrm{~d}^{9}$ electron in octahedral and tetragonal crystal field

From the Table-3 it is understood that among the glasses studied, the direct and indirect bandgaps are minimum and Urbach energy is maximum for $\mathrm{Cu}_{10}$ glass. Also, the data shows nonlinear variation in bandgap energies in the studied glasses. It is because of the change in NBO with variation in alkali ratio $(\mathrm{Na} / \mathrm{K})$. These observations strengthen that the structural changes of glass due to the mixed alkali phenomenon. Similar reports have been observed in other host glasses also. ${ }^{14,15}$

\section{Photoluminescence Studies}

When oxide glasses are excited by UV radiation, charge transfer bands are formed due to oxygen ligands around the cation. The Charge transfer from ligand to metal results in emission bands. All the present 
glasses detect invisible radiation, provided if they are exposed to radiation of wavelengths at $250 \mathrm{~nm}$ and $820 \mathrm{~nm}$ and are shown in Fig.-7.

By exciting with UV radiation blue emission centers at $452 \mathrm{~nm}$ and $470 \mathrm{~nm}$ are found for all studied glasses. When excited in the infrared region at $820 \mathrm{~nm}$ wavelength corresponding to ${ }^{2} \mathrm{~B}_{1 \mathrm{~g}} \rightarrow{ }^{2} \mathrm{~B}_{2 \mathrm{~g}}$ transition, red luminescence is observed. Blue and red emissions are reported in copper doped glasses earlier also. ${ }^{16,17}$ Hence these glasses are useful as invisible radiation sensor materials. Also, the present glasses could be employed in display technology.
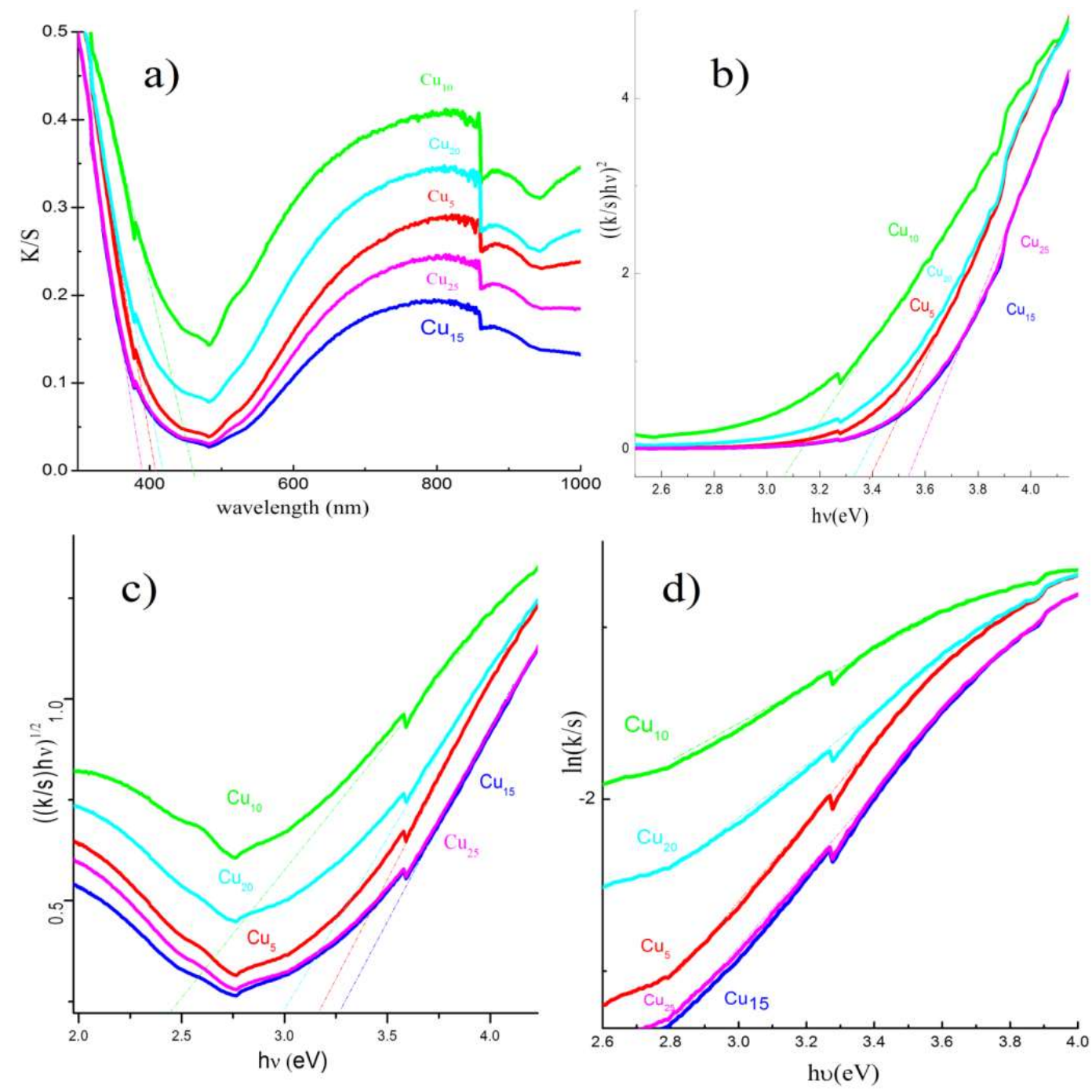

Fig.-6:(a) Reflectance spectra of $38 \mathrm{SiO}_{2}-30 \mathrm{~B}_{2} \mathrm{O}_{3}-\mathrm{xNa}_{2} \mathrm{O}-(30-\mathrm{x}) \mathrm{K}_{2} \mathrm{O}-2 \mathrm{CuO}$ glasses ;Tauc Plots to calculate (b) direct energy bandgaps ; (c) indirect energy bandgaps ; (d) Urbach energy of $38 \mathrm{SiO}_{2}-30 \mathrm{~B}_{2} \mathrm{O}_{3}-\mathrm{xNa}_{2} \mathrm{O}-(30-\mathrm{x}) \mathrm{K}_{2} \mathrm{O}-$

$2 \mathrm{CuO}$ glassesusing Kubelka- Munk function

\section{EPR Spectra}

EPR technique is employed to understand the arrangement of the ligands on $\mathrm{Cu}^{2+}$ ions and the covalent nature of the metal-ligand bonds in glasses. The association of electron spin with the spin of the copper nucleus (I) $=\frac{3}{2}$, a four-line hyperfine splitting is observed and is conveyed through Fig.-8(a). In the studied glasses in between $200-300 \mathrm{mT}$ applied magnetic field three parallel components are observed and the last parallel peak is partly covered with perpendicular peak. The Perpendicular signal components formed between 320-340 $\mathrm{mT}$ are not resolved well. EPR spectral lines are broadened because of the more dipolar interaction of $\mathrm{Cu}^{2+}$ with ligands, which may be because of a higher concentration of $\mathrm{Cu}^{2+}$ ions. 
The computed g-factors show that $\mathrm{g}_{\|}>\mathrm{g}_{\perp>} \mathrm{g}_{\mathrm{e}}(2.0023)$. This recommends that the octahedral site of $\mathrm{Cu}^{2+}$ ion has tetragonal elongation due to Z-out john - Teller distortion and the ground state is ${ }^{2} B_{1 g}\left(d_{x 2-y 2}\right)$. Spin- Hamiltonian for paramagnetic ions of EPR spectra is interpreted by Abragam and Pryce ${ }^{18}$. Bleany and Abragam gave an expression for spin Hamiltonian $\hat{H}$ for a paramagnetic ion in tetragonal axial distortion along the $\mathrm{z}$-axis in EPR spectra as in expression (1). ${ }^{19}$

$$
\hat{\mathrm{H}}=\beta_{\mathrm{e}} \mathrm{g}_{\|} \mathrm{B}_{\mathrm{z}} \mathrm{S}_{\mathrm{z}}+\beta_{\mathrm{e}} \mathrm{g}_{\perp}\left(\mathrm{B}_{\mathrm{x}} \mathrm{S}_{\mathrm{x}}+\mathrm{B}_{\mathrm{y}} \mathrm{S}_{\mathrm{y}}\right)+\mathrm{A}_{\|} \mathrm{S}_{\mathrm{z}} \mathrm{I}_{\mathrm{z}}+\mathrm{A}_{\perp}\left(\mathrm{I}_{\mathrm{x}} \mathrm{S}_{\mathrm{x}}+\mathrm{I}_{\mathrm{y}} \mathrm{S}_{\mathrm{y}}\right)
$$
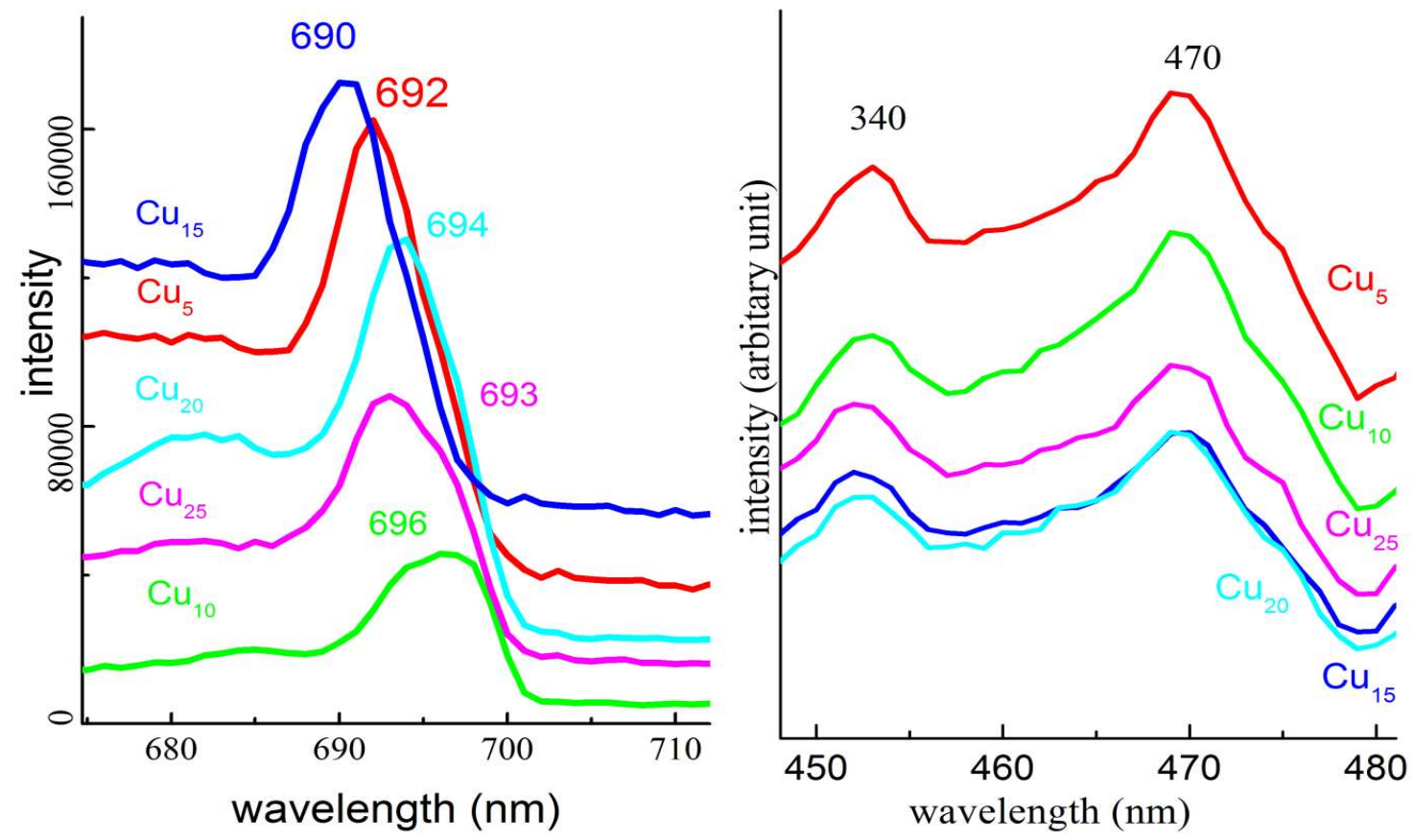

Fig.-7: Photo luminescence spectrum of $38 \mathrm{SiO}_{2}-30 \mathrm{~B}_{2} \mathrm{O}_{3}-\mathrm{xNa}_{2} \mathrm{O}-(30-\mathrm{x}) \mathrm{K}_{2} \mathrm{O}-2 \mathrm{CuO}$ glasses (a) at excitation wavelength $800 \mathrm{~nm}$; (b) at excitation wavelength $250 \mathrm{~nm}$

Perturbation due to ligand field leads to nonlinear deviation in Spin Hamiltonian parameters in studied glasses. $g$ value depends on the local magnetic field and it differs from unpaired electron $\mathrm{g}_{\mathrm{e}}=2.0023$ for transition metals because of their large spin-orbit coupling constant $\lambda$ and of their low transitional energies from which we get information about ligand - central metal atom bond. In copper complexes, $g$ shift was positive due to their filled orbitals. The degree of tetragonal distortion was calculated by a parameter G.

$$
\mathrm{G}=\frac{\mathrm{g} \|-\mathrm{ge}}{\mathrm{g} \perp-\mathrm{ge}}
$$

$\mathrm{G}$ magnitude is nearer to 5 in studied glasses suggests strong magnetic coupling among non-equivalent $\mathrm{Cu}^{2+}$ ions. Less degree of tetragonal distortion means the axial ligands do not move much away from $\mathrm{d}_{\mathrm{xy}} \&$ $\mathrm{d}_{\mathrm{xz}}, \mathrm{d}_{\mathrm{yz}}$; orbitals of central metal ion and so $\mathrm{E}_{\mathrm{xy}}$ and $\mathrm{E}_{\mathrm{xz}}$, yz energies increase. $\Delta \mathrm{E}_{\mathrm{xy}}$ and $\Delta \mathrm{E}_{\mathrm{xz}}$ are $\mathrm{E}_{\mathrm{xy}} \rightarrow \mathrm{E}_{\mathrm{x} 2-\mathrm{y} 2}$ and $E_{x z}, y z \rightarrow E_{x 2-y 2}$ transition energies respectively. ${ }^{20,21}$

$\mathrm{P}$ is Dipolar distortion constant and $\kappa$ is Fermi contact term. These two parameters are measures of anisotropic and isotropic interactions of electrons magnetic moment with the nucleus magnetic moment. ${ }^{22}$

$$
P=2 \gamma_{\mathrm{Cu}} \beta_{\mathrm{o}} \beta_{\mathrm{N}}\left(\mathrm{r}^{-3}\right)=0.036 \mathrm{~cm}^{-1}
$$

Here, copper ion magnetic moment is denoted as $\gamma_{\mathrm{Cu}}$, Bohr magneton with $\beta$ o, nuclear magneton with $\beta_{\mathrm{N}}$ and the separation from the nucleus center to the outer electron with $\mathrm{r}$.

$\kappa$ quantifies a part of the hyperfine splitting induced by ' $\mathrm{s}$ ' electrons because of the symmetric orbital shape and closest position of s- orbital to the nucleus.

$$
\kappa=\left(\frac{A \text { iso }}{P}\right)+\Delta \mathrm{g}_{\text {iso }}
$$


RASĀYAN J. Chem.

Vol. 14 | No. 3 |2136-2146| July - September | 2021

$$
\begin{aligned}
& g_{\text {iso }}=\frac{(2 g \perp+g \|)}{3} \\
& A_{\text {iso }}=\frac{(2 A \perp+A \|)}{3}
\end{aligned}
$$

And $\Delta \mathrm{g}_{\text {iso }}=g_{\text {iso }}-g_{\mathrm{e}}$, and $g_{\mathrm{e}}=2.0023$ (free electron).

The calculated value of $\kappa \sim 0.31$, coincides with the standard value of $\kappa$ in copper complexes and it is an independent property of $\mathrm{Cu}^{2+}$ ion. The calculated values of spin-Hamiltonian parameters and bonding coefficients are indicated in Table-4.

\begin{tabular}{|c|c|c|c|c|c|c|c|c|c|c|c|}
\hline \multirow{2}{*}{ GlassCode } & \multirow[b]{2}{*}{$g_{\|}$} & $\mathrm{A}_{\|}$ & \multirow[b]{2}{*}{$\mathrm{g}_{\perp}$} & $\mathrm{A}_{\perp}$ & \multirow{2}{*}{ G } & \multirow{2}{*}{$\alpha^{2}$} & \multirow{2}{*}{$\beta_{1}^{2}$} & \multirow{2}{*}{$\beta^{2}$} & \multirow[b]{2}{*}{$\kappa$} & \multirow{2}{*}{$\Gamma_{\sigma}$} & \multirow{2}{*}{$\Gamma_{\Pi}$} \\
\hline & & $10^{-4} \mathrm{~cm}^{-1}$ & & $10^{-4} \mathrm{c} \mathrm{m}^{-1}$ & & & & & & & \\
\hline $\mathrm{Cu}_{5}$ & 2.23 & 141 & 2.05 & 33 & 4.7 & 0.68 & 0.31 & 1.2 & 0.31 & 127 & 62.8 \\
\hline $\mathrm{Cu}_{10}$ & 2.3 & 125 & 2.05 & 37 & 6.2 & 0.70 & 0.38 & 1.1 & 0.30 & 123 & 64.8 \\
\hline $\mathrm{Cu}_{15}$ & 2.28 & 139 & 2.05 & 30 & 5.7 & 0.72 & 0.36 & 1.1 & 0.31 & 128 & 61.0 \\
\hline $\mathrm{Cu}_{20}$ & 2.29 & 133 & 2.05 & 25 & 6.1 & 0.72 & 0.37 & 1.1 & 0.30 & 125 & 60.4 \\
\hline $\mathrm{Cu}_{25}$ & 2.27 & 135 & 2.05 & 26 & 5.6 & 0.70 & 0.35 & 1.1 & 0.29 & 129 & 64.7 \\
\hline
\end{tabular}

Table-4: Spin Hamiltonian Parameters and Molecular Orbital Coefficients

\section{Covalent Nature of Metal-Ligand Bond}

Spin Hamiltonian parameters of paramagnetic ions depend on separation between electrons and nuclei. This decides the nature of the bonds between transition metal ions and the ligands. Using hyperfine splitting parameters molecular bonding coefficient $\alpha^{2}$ is calculated by Kuska's formula. ${ }^{23}$

$\alpha^{2}=\frac{7}{6}\left\{\left(\frac{\mathrm{A} \|}{P}\right)+(\mathrm{g} \|-\mathrm{ge})+\frac{3}{7}(\mathrm{~g} \perp-\mathrm{ge})+0.04\right\}$

The Spin Hamiltonian splitting parameters are correlated with electron energy levels measured from optical absorption data. This gives information about the interaction of central molecular ion $\mathrm{Cu}^{2+}$ with its chemical environment. ${ }^{24}$ Using Kłonkowski formulae the bonding parameters $\beta_{1}{ }^{2}$ and $\beta^{2}$ are calculated. ${ }^{25}$

$$
\begin{aligned}
& g_{\|}=g_{e}\left[1-\frac{4 \alpha^{2} \beta 1^{2} \lambda}{\Delta \text { Exy }}\right] \\
& g_{\perp}=g_{e}\left[1-\frac{\alpha^{2} \beta^{2} \lambda}{\Delta \text { Exz,yz }}\right]
\end{aligned}
$$

Figure-8(b) depicts the variation of covalent nature of ligand-metal bond with alkali ratio. The normalized covalencies $\Gamma_{\sigma}, \Gamma_{\Pi}$ of $\mathrm{Cu}^{2+}$-O inplane $\sigma$ - and inplane $\Pi$ - bonds are calculated using formulas (12), (13) given below. $\Gamma_{\Pi}$ and $\Gamma_{\sigma}$ are proportional to the covalent nature of $\mathrm{Cu}^{2+}-\mathrm{O}$ bond.

$$
\begin{aligned}
& \Gamma_{\sigma}=\frac{200(1-S)\left(1-\alpha^{2}\right)}{1-2 S} \% \\
& \Gamma_{\Pi}=200\left(1-\beta_{1}^{2}\right) \%
\end{aligned}
$$

Where $\mathrm{S}=0.076$ is overlap integral and is due to the overlap of copper $\mathrm{d}_{\mathrm{x} 2 \mathrm{y} 2}$ orbital with ligand orbitals. The SHP and distortion parameters $\mathrm{P}, \kappa$ from EPR spectra and bonding parameters are calculated correlating with absorption spectrum and values are tabulated in Table- 4 and all resemble the values obtained in previous studies on $\mathrm{Cu}^{2+}$ doped glasses. ${ }^{26-29}$ From the calculated metal-ligand wave functions $\alpha^{2}, \beta_{1}^{2}, \beta^{2}$ it is found that the in-plane $\sigma$ - bond and inplane $\Pi$ bond formed among transition metal ion-ion and the ligands is moderately covalent and out of a plane $\Pi$ - bonding is ionic respectively.

The lower value of $\alpha^{2}>0.5$ suggests that the electrons in $\mathrm{d}_{\mathrm{x} 2-\mathrm{y} 2}$ orbital are more localized on copper atom than ligand and in plane $\sigma$ bond among Copper ion and the ligands is moderately covalent. Similarly $\beta^{2}<$ 0.5 indicates $d_{x y}$ electrons are more shared by ligand orbitals than a metal atom. The low value of $\alpha^{2}=$ $0.68, \beta^{2}=0.31$ for $\mathrm{Cu}_{5}$ than other glasses of this series indicate better covalency of bonds in this glass and less z-out tetragonal distortion. This is also supported by the low value of tetragonal distortion measure $\mathrm{G}$ 
$=4.7$ for $\mathrm{Cu}_{5}$. Similarly higher tetragonal elongation of $\mathrm{Cu}_{10}$ is also explained by more localization of $\mathrm{d}_{\mathrm{x} 2-}$ y2 orbital on metal atom $\left(\alpha^{2}=0.70\right)$ and $\mathrm{d}_{\mathrm{xy}}$ electrons $\left(\beta^{2}=0.38\right)$ than other glasses of this series. So $\mathrm{Cu}_{10}$ is more ionic, this is also strengthened from the metallization criterion values evaluated in Table 3 . Higher normalized covalency $\Gamma_{\sigma}$ and low $\Gamma_{\Pi}$ for $\mathrm{Cu}_{10}$ also confirms the same.

These results suggest MAE phenomenon in present glasses. From the calculated metal-ligand wave functions $\alpha^{2}, \beta_{1}^{2}, \beta^{2}$ it is found that the in-plane $\sigma$ - bond and in-plane $\Pi$ - bonding between Copper ion and its ligands is moderately covalent and out of a plane $\Pi$ - bonding is ionic respectively.

a)

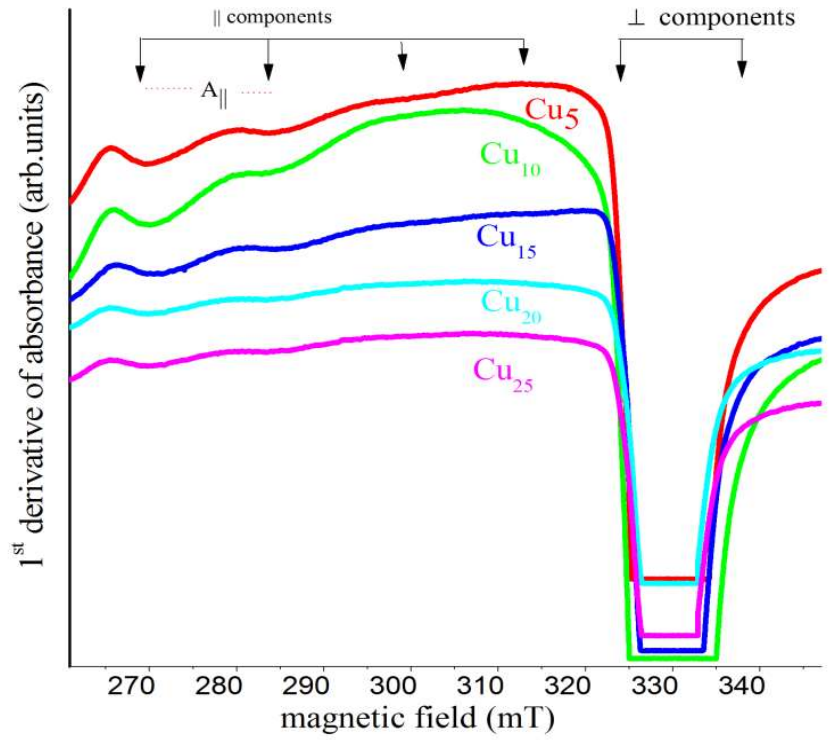

b)

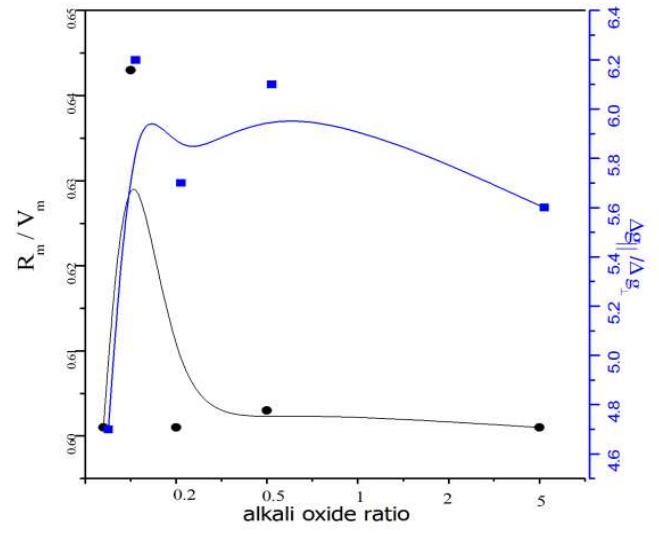

Fig.-8: (a) EPR spectra of $\mathrm{Cu}^{2+}$ ion of $38 \mathrm{SiO}_{2}-30 \mathrm{~B}_{2} \mathrm{O}_{3}-\mathrm{xNa}_{2} \mathrm{O}-(30-\mathrm{x}) \mathrm{K}_{2} \mathrm{O}-2 \mathrm{CuO}$ glasses (b) Dependence of ionic nature on tetragonal distortion $\left(\mathrm{G}=\frac{\Delta \mathrm{g} \|}{\Delta \mathrm{g} \perp}\right)$

\section{Vibrational Spectra of Glasses}

Using vibrational spectra, structural groups present in glasses can be known. Infrared spectra of materials are sketched in the region $400-4000 \mathrm{~cm}^{-1}$. The bands present in our investigating glasses are represented in Fig. -9 and the assigned bands in Table-5.

The band centers at 450 and $470 \mathrm{~cm}^{-1}$ in FTIR spectra indicate the existence of $\mathrm{SiO}_{4}$ tetrahedra. ${ }^{30,31}$ The presence of Silica phase $\left(\mathrm{SiO}_{4}\right.$ tetrahedra) in glass indicates less corrosiveness of studied glasses. Due to high alkali content (30\%) boroxol rings are replaced by other borate structural units. This was evident by the replacement of the band at $808 \mathrm{~cm}^{-1}$ with $720 \mathrm{~cm}^{-1}$ band. The presence of asymmetric stretching vibration bonds of $\left(\mathrm{BO}_{3}\right)^{3-}$ entities of pyro borates ${ }^{30}$ is also revealed by the band centers at $875 \mathrm{~cm}^{-1}, 1265 \mathrm{~cm}^{-1}, 1415-1453 \mathrm{~cm}^{-1}$. Asymmetric vibrational modes of $\mathrm{SiO}_{4}$ with one NBO are also confirmed by the bands at 1020 and $1050 \mathrm{~cm}^{-1}$. Weak Si-O-B band at $670 \mathrm{~cm}^{-1}$ also informs boron ions are not incorporated much in silica network. $^{31,32}$

Table-5: Wavenumber assignment to infrared transmittance band of $38 \mathrm{SiO}_{2}-30 \mathrm{~B}_{2} \mathrm{O}_{3}-\mathrm{xNa}_{2} \mathrm{O}-(30-\mathrm{x}) \mathrm{K}_{2} \mathrm{O}-2 \mathrm{CuO}$ glasses $(x=5,10,15,20,25)$

\begin{tabular}{c|c|c}
\hline S. No. & Centre of Band Position & Assigned Band \\
\hline 1 & 455,470 & Si-O-Si symmetric vibrations of $\mathrm{SiO}_{4}$ tetrahedra \\
\hline 2 & 670 & bending vibration of $\mathrm{B}-\mathrm{O}-\mathrm{Si}$ \\
\hline 3 & 720 & bending mode of $\mathrm{B}-\mathrm{O}-\mathrm{B}$ center \\
\hline 4 & 875 & stretching vibrations of tetrahedral $\mathrm{BO}_{4}{ }^{-}$units \\
\hline 5 & 1020 & $\mathrm{SiO}_{4}$ with one $\mathrm{NBO}$ \\
\hline 6 & $1415-1453$ & antisymmetric stretching vibration of $\mathrm{BO}_{3}$ \\
\hline
\end{tabular}


RASĀYAN J. Chem.

Vol. 14 | No. 3 |2136-2146| July - September | 2021

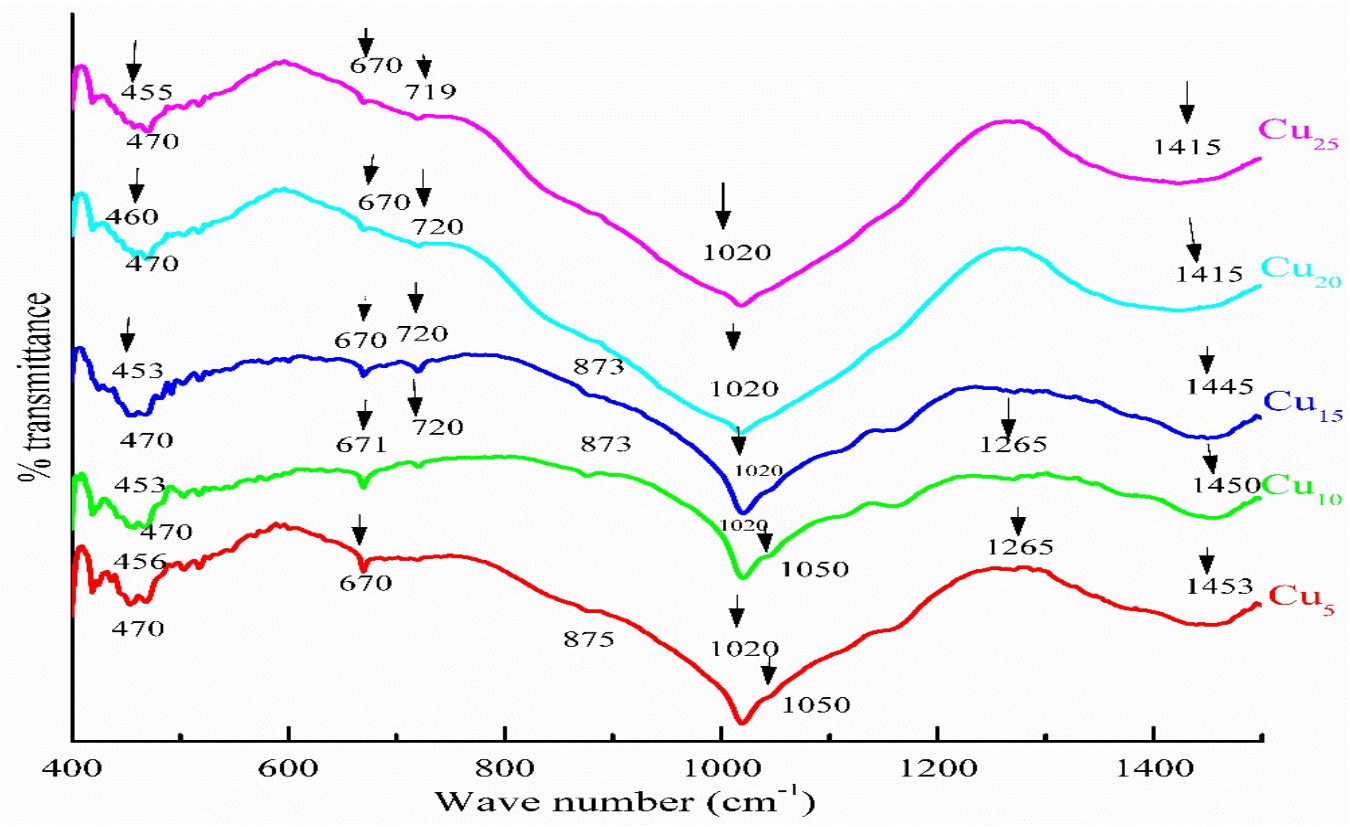

Fig.-9: FTIR spectra of $38 \mathrm{SiO}_{2}-30 \mathrm{~B}_{2} \mathrm{O}_{3}-\mathrm{xNa}_{2} \mathrm{O}-(30-\mathrm{x}) \mathrm{K}_{2} \mathrm{O}-2 \mathrm{CuO}$ glasses

\section{CONCLUSION}

The studied non- crystalline glassy materials surface smoothness decreases with doping $\mathrm{Cu}^{2+}$ ions. This indicates there is a change in the structure of glass by doping transition metal ions. The glasses may have good ductile nature because of their large supercooled liquid range $\Delta \mathrm{T}_{\mathrm{c}}=189^{\circ} \mathrm{C}$. Nonlinear variation in bandgaps is observed due to the Mixed Alkali Effect phenomenon. Metallization criterion values indicate these inorganic glasses are non-metals and $\mathrm{Cu}_{10}$ glass is less covalent than other glasses. The studied glasses exhibit blue and red fluorescence when excited in UV region and IR region respectively. The Hamiltonian parameters confirm the tetragonal elongated octahedron site of $\mathrm{Cu}^{2+}$ ion. The bonding parameters $\alpha^{2}, \beta_{1}^{2}$ estimate that the in-plane $\sigma$ - bond and in plane $\Pi$ bonding among Copper ion and the ligands is moderately covalent. The trend of $\frac{R m}{V m}$ which measures the metallic nature of glasses obtained from bandgaps is similar to the tetragonal distortion. FTIR spectra identify the vibrational bands corresponding to various structural groups of borate $\mathrm{BO}_{4}$ tetrahedra, $\mathrm{BO}_{3}$ triangles, $\mathrm{B}-\mathrm{O}-\mathrm{Si}$ linkages and also of vitreous Silica phase in studied glasses.

\section{REFERENCES}

1. Weidong Xiang, HaihongGao, Li Ma, Xin Ma, Yunyun Huang, Lang Pei and Xiaojuan Liang, ACS Applied Materials and Interfaces, https://doi.org/10.1021/acsami.5b00218

2. Francesco Baino, SepidehHamzehlou and_SaeidKargozar, Functional Biomaterials, 9(1), 25 (2018), https://doi.org/10.3390/jfb9010025

3. F. Foroutan, J. McGuire, P. Gupta , A.Nikolaou, BA.Kyffin , NL.Kelly, JV.Hanna , J. Gutierrez-Merino, JC.Knowles ,SY. BaekandandE. Velliou, ACS Biomaterials Science \& Engineering, 5(11), 6054(2019), https://doi.org/10.1021/acsbiomaterials.9b01291

4. R. W. Frei, Research of the National Bureau Standards. SectionA. Physics and Chemistry, 80A(4), (1976), https://doi.org/10.6028/jres.080A.055

5. A.Escobedo-Morales,M.deL.Ruiz-Peralta, L.Tepech-Carrillo, M.Sánchez-Cantú,and J.E.MorenoOrea, Heliyon, 5, e01505(2019), https://doi.org/10.1016/j.heliyon.2019.e01505

6. Li Yang and B. Kruse, Journal of the Optical Society of America, 21(10), 1933(2004).

7. M. Rajesh Yadav, B. Jaya Raja, M. Avinash, Ch. Rama Krishna and R. V. S. S. N. Ravikumar, Materials Science: Materials in Electronics, 27, 1318(2016), https://doi.org/10.1007/s10854$\underline{015-3892-4}$ 
RASĀYAN J. Chem.

Vol. 14 | No. 3 |2136-2146| July - September | 2021

8. F. Auzel, spectroscopy of solid state lasers, Plenum Press, Newyork (1987), https://doi.org/10.1007/978-1-4613-0899-7 10

9. J. A. Duffy, Journal of Solid State Chemistry,62(2), 145(1986), https://doi.org/10.1016/00224596(86)90225-2

10. O.I .Sallam, A. Abdeldaym, and F.M. Ezz-Eldin, Materials Chemistry and Physics, 252, 123241(2020), https://doi.org/10.1016/j.matchemphys.2020.123241

11. B. Ashok, A . Hameed, B. Srinivas, , G. Ramdevudu and , M .N Chary, i-Manager's Journal on Material Science, 8(2), 9 (2020).

12. J. Tauc, R. Grigoroviceand A. Vancu, Physica Status Solidi (b),15, 627(1996), https://doi.org/10.1002/pssb.19660150224

13. E.A. Davis and N.F. Mott, ThePhilosophical Magazine: A Journal of Theoretical Experimental and Applied Physics, 23, 2500(1970), https://doi.org/10.1080/14786437008221061

14. S. Kojima, Solids, 1(1), 16 (2020), https://doi.org/10.3390/solids1010003

15. C. Calahoo, Y.Xia, R. Zhou, International Journal of Applied Glass Science, 11(3), 396 (2020).

16. R. Hashikawa, Y. Fujii, A. Kinomura, T. Saito, A. Okada, T. Wakasugi, K. Kadono, Journal of the American Ceramic Society, 102(4),1642(2019).

17. M.A. Ouis, M.A.Marzouk, Journal of Luminescence, 1(223), 117242(2020).

18. A. Abragam and M.H.L. Pryce, Proceedings of The Royal SocietyA, 205, 135(1951), https://doi.org/10.1098/rspa.1951.0022

19. B. Bleaney and A. Abragam, Electron Paramagnetic Resonance of Transition Ions, Clarendon Press, Oxford p. 650 (2013).

20. Chee Chow, Kun Chang and R.D. Willet, Chemical Physics, 59, 2629(1973), https://doi.org/10.1063/1.1680380

21. D. Kivelson and R. Neiman, Chemical Physics, 35, 145(1961), https://doi.org/10.1063/1.1731880

22. G. Fuxi, Optical Spectroscopic Properties of Glass (Berlin; Springer) 1992.

23. H.A. Kuska, M.T. Rogers and R.E. Durllinger, Physics and Chemistry,71(1), 109(1967), https://doi.org/10.1021/j100860a015

24. R.M. Krishna and S.K. Gupta, Bulletin of Magnetic Resonance, 16(3-4), 239(1994).

25. A. Klonkowski, Physics and Chemistry of Glasses, 24, 166(1983), https://doi.org/10.1016/S0022-3093(87)80134-5

26. A.K. Maki and B.R. Mcgarvey, Chemical Physics, 29, 31(1958), https://doi.org/10.1063/1.1744456

27. V. Kumar Chavan, M. Sreenivasulu, and B.R.V. Rao, Optik, 221, 16529(2020), https://doi.org/10.1016/j.ijleo.2020.165291

28. O.I. Sallam, A. Alhodaib, S. Abd El Aal, and F.M. Ezz-Eldin, Inorganic Chemistry Communications, 124, 108388(2021), https://doi.org/10.1016/j.inoche.2020.108388

29. J.S. Krishna, D.S. Raju, V.V. Krishna, and C. L. Raju, In Proceedings of international Conference on Research Frontiers in Sciences (ICRFS 2021) 5th-6th February 2021, Nagpur, India, Journal of Physics: Conference Series, IOP Publishing, 1913(1), 012013( 2021).

30. W. B. White, S. A. Brawer, T. Furukawa and G.J. McCarthy, Structure of Borate Glasses by Raman Spectroscopy, in: L.D. Pye ,V. D. Frechette and N.J. Kreidl, (Eds), Borate Glasses. Materials Science Research, Vol 12. Springer, Boston, MA, pp. 281-296 (1978), https://doi.org/10.1007/978-1-4684-3357-9 12

31. B. Nagamani and Ch. Srinivasu, Material Research Express , 7(1), 015207(2020), http://dx.doi.org/10.1088/2053-1591/ab67f6

32. W. L. Konijnendijk and J. M. Stevels, Non-Crystalline Solids, 18, 307(1975), https://doi.org/10.1016/0022-3093(75)90137-4

[RJC-5757/2020] 